\title{
General and microbiological aspects of solid substrate fermentation
}

\author{
Maurice Raimbault \\ Laboratoire de Biotechnologie Microbienne Tropicale, Centre ORSTOM-LBMT 911 av. Agropolis - B.P.:5045 - 34032 Montpellier (France) \\ E-mail: maurice.raimbault@mpl.orstom.fr
}

http://www.mpl.orstom.fr

\begin{abstract}
At first some general considerations about specificity and characteristics of SSF, their advantages and disadvantages as compared to LSF, are presented. Microorganisms involved in solid substrate fermentations are identified, considering the better performances of filamentous fungi. The solid substrates and their basic macromolecular compounds are detailed in relation to this complex and heterogeneous system. Biomass measurement is examined in detail, as well as environmental factors, both essential for studying and optimising solid substrate fermentations.
\end{abstract}

\section{General considerations}

Aerobic microbial transformation of solid materials or "Solid Substrate Fermentation" (SSF) can be defined in terms of the following properties:

- A solid porous matrix which can be biodegradable or not, but with a large surface area per unit volume, in the range of $10^{3}$ to $10^{6} \mathrm{~m}^{2} / \mathrm{cm}^{3}$, for a ready microbial growth on the solid/gas interface.

- The matrix should absorb water amounting one or several times its dry weight with a relatively high water activity on the solid/gas interface in order to allow high rates of biochemical processes.

- Air mixture of oxygen with other gases and aerosols should flow under a relatively low pressure and mix the fermenting mash.

- The solid/gas interface should be a good habitat for the fast development of specific cultures of moulds, yeasts or bacteria, either in pure or mixed cultures.

- The mechanical properties of the solid matrix should stand compression or gentle stirring, as required for a given fermentation process. This requires small granular or fibrous particles, which do not tend to break or stick to each other.

- The solid matrix should not be contaminated by inhibitors of microbial activities and should be able to absorb or contain available microbial foodstuffs such as carbohydrates (cellulose, starch, sugars) nitrogen sources (ammonia, urea, peptides) and mineral salts.
Typical examples of SSF are traditional fermentations such as:

- Japanese "koji" which uses steamed rice as solid substrate inoculated with solid strains of the mould Aspergillus oryzae.

- Indonesian "tempeh" or Indian "ragi" which use steamed and cracked legume seeds as solid substrate and a variety of non toxic moulds as microbial seed.

- French "blue cheese" which uses perforated fresh cheese as substrate and selected moulds, such as Penicillium roquefortii as inoculum.

- Composting of lignocellulosic fibres, naturally contaminated by a large variety of organisms including cellulolytic bacteria, moulds and Streptomyces $s p$.

- In addition to traditional fermentations, new versions of SSF have been invented. For example, it is estimated that nearly a third of industrial SSF and koji processes in Japan has been modernised for large scale production of citric and itaconic acids.

Furthermore, new applications of SSF have been suggested for the production of antibiotics (Barrios et al., 1988), secondaries metabolites (Trejo-Hernandez et al., 1992, 1993) or enriched foodstuffs (Senez et al., 1980).

Presently SSF has been applied to large-scale industrial processes mainly in Japan. Traditional koji, manufactured in small wooden and bamboo trays, has changed gradually to more sophisticated processes: fixed bed room fermentations, rotating drum processes and automated stainless steel chambers or trays with microprocessors, electronics sensors and servomechanical stirring, loading and discharging. The usual scale in sake or miso factories is around 1 or 2 metric tons per batch, but reactors can be made and delivered by engineering firms to a capacity as large as 20 tons (Fujiwara, Ltd.).

Outside Japan, Kumar (1987) has reported medium scale production of enzymes, such as pectinases, in India. Koji type processes are widely used in small factories of the Far East (Hesseltine, 1972) and koji fermentation has been adapted to local conditions in United States (USA) and other Western countries, including Cuba (III A). In France, a new firm (Lyven S.A.) was recently created to 
commercialise a process for pectinase production from sugarbeet pulp. Blue cheese production in France is being modernised with improvements on the mechanical conditioning of cheeses, production of mould spores and control of environmental conditions.

Composting, which was developed for small-scale production of mushrooms, has been modernised and scaled up in Europe and USA. Also, various firms in Europe and USA produce mushroom spawn by cultivating Agaricus, Pleurotus or Shii-Take aseptically on sterile grains in static conditions.

New versions for SSF reactors have been developed in France (Durand et al., 1988; Roussos et al., 1993, Durand et al., 1997), Cuba (Cabello, 1985; Enríquez, 1983 and Rodríguez, 1986), Chile (Fernández et al., 1996) and fundamental studies on process engineering are being conducted in Mexico (Saucedo-Castañeda, 1990).

SSF is a batch process using natural heterogeneous materials (Raimbault, 1981 and Tengerdy, 1985), containing complex polymers like lignin (Agosin et al, 1989), pectin
(Kumar, 1987; Oriol, 1988a), lignocellulose (Roussos, 1985). SSF has been focused mainly to the production of feed, hydrolytic enzymes, organic acids, gibberelins, flavours and biopesticides.

Most of the recent research activity on SSF is being done in developing nations as a possible alternative for conventional submerged fermentations, which are the main process in pharmaceutical and food industries in industrialised nations.

SSF seems to have theoretical advantages over liquid substrate fermentation (LSF). Nevertheless, SSF has several important limitations. Table 1 shows advantages and disadvantages of SSF compared to LSF.

Table 2 presents a list of SSF processes in economical sectors of agro-industry, agriculture and fermentation industry. Most of the processes are commercialised in South-East Asian, African, and Latin American countries. Nevertheless, a resurgence of interest has occurred in Western and European countries over the last 10 years. The future potentials and applications of SSF for specific processes are discussed later.

Table 1. Comparison between Liquid and Solid Substrate Fermentations.

\begin{tabular}{|c|c|c|}
\hline FACTOR & $\begin{array}{l}\text { Liquid } \\
\text { Substrate Fermentation }\end{array}$ & $\begin{array}{l}\text { Solid } \\
\text { Substrate Fermentation }\end{array}$ \\
\hline & Soluble Substrates (sugars) & Polymer Insoluble Substrates: \\
\hline Sub strates & & Starch Cellulose Pectines Lignin \\
\hline Aseptic conditions & $\begin{array}{l}\text { Heat sterilisation and aseptic } \\
\text { Control }\end{array}$ & $\begin{array}{l}\text { Vapor treatment, non sterile } \\
\text { conditions }\end{array}$ \\
\hline Water & $\begin{array}{l}\text { High volumes ofwaterconsu-med } \\
\text { and effluents discarded }\end{array}$ & $\begin{array}{l}\text { Limited Consumption of Wa-ter; } \\
\text { low Aw. No effluent }\end{array}$ \\
\hline Metabolic Heating & Easy control of temperature & $\begin{array}{l}\text { Low heat transfer capacity } \\
\text { Easy aeration and high surfa ce } \\
\text { exchange air/substrate }\end{array}$ \\
\hline Aeration & $\begin{array}{l}\text { Limitation oby soluble oxygen High } \\
\text { level of air required }\end{array}$ & \\
\hline pH control & Easy $\mathrm{pH}$ control & Buffered solid substrates \\
\hline Mecanical agitation & Good homogeneization & Static conditions prefered \\
\hline Scale up & Industrial equipments Available & $\begin{array}{l}\text { Need for Engineering \& New } \\
\text { design Equipment }\end{array}$ \\
\hline Inoculation & $\begin{array}{l}\text { Easy inoculation , continuous } \\
\text { process }\end{array}$ & Spore inoculation, batch \\
\hline Contamination & $\begin{array}{l}\text { Risks of contamination for single } \\
\text { strain bacteria }\end{array}$ & $\begin{array}{l}\text { Risk of contamination for low rate } \\
\text { growth fungi }\end{array}$ \\
\hline Energetic consideration & High energy consuming & Low energy consuming \\
\hline Volume of Equipment & $\begin{array}{l}\text { High volumes and high cost } \\
\text { technology }\end{array}$ & $\begin{array}{l}\text { Low volumes \&low costs of } \\
\text { equipments }\end{array}$ \\
\hline
\end{tabular}




\begin{tabular}{|l|l|l|}
\hline Effluent \& pollution & High volumes of polluting effluents & No effluents, less pollution \\
\hline Concentration S /Products & $30-80 \mathrm{~g} / 1$ & $100 / 300 \mathrm{~g} / 1$ \\
\hline
\end{tabular}

The following considerations summarise the present status of SSF:

- Potentially many high value products, as enzymes, primary and secondary metabolites, could be produced in SSF. But improvements in engineering and socio-economic aspects are required because processes must use cheap substrates locally available, low technology applicable in rural areas, and processes therefore must be simplified.

- Potential exists in developed countries, but close co-operation and exchange between developing and industrialised countries are required for further application of SSF.

- The greatest socio-economical potential of SSF is the raising of living standards through the production of protein rich foods for human consumption. Protein deficiency is a major cause of malnutrition and the problem will become worse with further increases in world population. Two alternatives can be explored to tackle this problem:

- Production of protein-enriched fermented foods for direct human consumption. This alternative involves starchy substrates for its initial nutritional caloric value. Successful production of such foods will require demonstration of economical feasibility, safety, significant nutritional improvement, and cultural acceptability.

- Production of fermented materials for animal feeding. Starchy substrates protein-enriched by SSF could be fed to monogastric animals or poultry. Fermented lignocellulosic substrates, by increasing its fibre digestibility, could be fed to ruminants. In this case, the economical feasibility should be favourable in comparison to the common model using protein of soybean cake, a by-product of soybean oil. product of soybean oil.

Table 2. Main applications of SSF processes in various economical sectors

\begin{tabular}{|l|l|l|}
\hline \multicolumn{1}{|c|}{ Economical Sector } & \multicolumn{1}{|c|}{ Application } & \multicolumn{1}{c|}{ Examples } \\
\hline Agro-Food Industry & Traditional Food Fermentations & $\begin{array}{l}\text { Koji, Tcznpch, Rae, Attickc, } \\
\text { Fermented cheeses }\end{array}$ \\
\hline & Mushroom Production \& spawn & Agaricus, Pleurotus, Shn-take \\
\hline & Bioconversion By-products & $\begin{array}{l}\text { Sugar pulp Bagass Coffee pulp' } \\
\text { Silage Composting, Detoxication }\end{array}$ \\
\hline Agriculture & Food Additives & $\begin{array}{l}\text { Flavours. Dyestuffs. Essential Fat } \\
\text { and organic acids }\end{array}$ \\
\hline & Biocontrol, Bioinsecticide & $\begin{array}{l}\text { Beauveria Metarhizium, Tricho } \\
\text { derma }\end{array}$ \\
\hline $\begin{array}{l}\text { Industrial } \\
\text { Fermentation }\end{array}$ & PlantGrowth, Hormones & $\begin{array}{l}\text { Gioberellins, Rhizobium, In- } \\
\text { choderma }\end{array}$ \\
\hline & Mycorhization, Wild Mushroom & Plant inoctiation, \\
\hline & Enzymes production & $\begin{array}{l}\text { Amylases, Cellulases Proteases, } \\
\text { Pectinases, Xylanases }\end{array}$ \\
\hline & Artibiotic prduction & Penecillin, feed \& Probiotics \\
\hline & Organic acid Production & $\begin{array}{l}\text { Ciric acid } \\
\text { Fumaric acid } \\
\text { Gallic acic } \\
\text { Lactic acid }\end{array}$ \\
\hline & Ethanol Prodixtion & $\begin{array}{l}\text { Schwanniomyces sp. Sbrch } \\
\text { Malting and Brewing }\end{array}$ \\
\hline & Fungal Metabolites & Hormones Alcaloides, \\
\hline
\end{tabular}

For the last 15 years, the Orstom group has been working on solid fermentation process for improving protein content of cassava and other tropical starchy substrates using fungi, specially from Aspergillus group, in order to transform starch and mineral salts into fungal proteins (Raimbault, 1981). 
More recently, C. Soccol working at our Orstom laboratory in Montpellier, obtained good results with fungi of the Rhizopus group, of special interest in human traditional fermented foods (Soccol, 1992). Increasing knowledge about specificity of strains of Rhizopus able to degrade crude granules of starch has been recently gathered at Orstom, which will drastically simplify the process of SSF. The ORSTOM group is also collaborating since 1981 with a group at the Universidad Autónoma Metropolitana (UAM) in Mexico on the following aspects:

- Protein enrichment of cassava and starchy substrates

- Production of organic acids or ethanol by SSF from starchy substrate and cassava

- Digestibility of fibres and lignocellulosic materials for animal feeding

- Degradation of caffein in coffee pulp and ensiling for conservation and detoxification

- Production of enzymes and fungal metabolites by SSF using sugarcane bagasse

Hopefully in the future, an extended collaborative program could be fitted for other Latin-American research groups involved in SSF, which might originate an international network including American, Asian, European and Australian groups.

\section{Microorganisms}

Bacteria, yeasts and fungi can grow on solid substrates, and find application in SSF processes. Filamentous fungi are the best adapted for SSF and dominate in research works. Some examples of SSF processes for each category of micro-organisms are reported in Table 3.

Bacteria are mainly involved in composting, ensiling and some food processes (Doelle et al., 1992). Yeasts can be used for ethanol and food or feed production (SaucedoCastañeda et al., 1992a, 1992b).

But filamentous fungi are the most important group of microorganisms used in SSF process owing to their physiological, enzymological and biochemical properties.
The hyphal mode of fungal growth and their good tolerance to low water activity $\left(\mathrm{A}_{\mathrm{w}}\right)$ and high osmotic pressure conditions make fungi efficient and competitive in natural microflora for bioconversion of solid substrates.

Koji and Tempeh are the two most important applications of SSF with filamentous fungi. Aspergillus oryzae is grown on wheat bran and soybean for Koji production, which is the first step of soy sauce or citric acid fermentation. Koji is a concentrated hydrolytic enzyme medium required in further steps of the fermentation process. Tempeh is an Indonesian fermented food produced by the growth of Rhizopus oligosporus on soybeans. People consume the fermented product after cooking or toasting. The fungal fermentation allows better nutritive quality and degrades some antinutritional compounds contained in the crude soybean.

The hyphal mode of growth gives a major advantage to filamentous fungi over unicellular microorganisms in the colonisation of solid substrates and for the utilisation of available nutrients. The basic mode of fungal growth is a combination of apical extension of hyphal tips and the generation of new hyphal tips through branching. An important feature is that, although extension occurs only at the tip at a linear and constant rate, the frequency of branching makes the kinetic growth pattern of biomass exponential, mainly in the first steps of the vegetative stage. That point is important for growth modelling and will be discussed further.

The hyphal mode of growth gives the filamentous fungi the power to penetrate into the solid substrates. The cell wall structure attached to the tip and the branching of the mycelium ensure a firm and solid structure. The hydrolytic enzymes are excreted at the hyphal tip, without large dilution like in the case of LSF, what makes the action of hydrolytic enzymes very efficient and allows penetration into most solid substrates. Penetration increases the accessibility of all available nutrients within particles.

Table 3. Main groups of microorganisms involved in SSF processes.

\begin{tabular}{|ll|}
\hline Microflora & SSF Process \\
Bacteria & \\
Bacillus sp. & Composting, Natto, amylase \\
Pseudomonas sp. & Composting \\
Serratia sp. & Composting \\
Streptoccus sp. & Composting \\
Lactobacillus sp. & Ensiling, Food \\
Clostidrium sp. & Ensiling, Food \\
& \\
Yeast & \\
Endomicopsis burtonii & Tape, cassava, rice \\
\hline
\end{tabular}




Saccharomyces cerevisiae
Schwanniomyces castelli
Fungi
Altemaria sp.
Aspergillus sp.
Fusarium sp.
Monilia sp.
Mucor sp.
Rhizopus sp.
Phanerochaete chrysosporium
Trichoderma sp.
Beauveria sp., Metharizium sp.
Amylomyces rouxii
Aspergillus oryzae
Rhizopus oligosporus
Aspergillus niger
Pleurotus oestreatus, sajor-caju
Lentinus edodes
Penicilium notatum, roquefortii

\author{
Food, Ethanol \\ Ethanol, Amylase
}

\author{
Composting \\ Composting, Industrial, Food \\ Composting. Gibberellins \\ Composting \\ Composting, Food; enzime
}

Composting. Food, enzimes, organic acids

Composting, lignin degradation

Composting Biological control, Bioinsecticide

Biological control, Bioinsecticide

Tape cassava, rice

Koji, Food, citric acid

Tempeh, soybean, amylase, lipase

Feed, Proteins, Amylase, ctric acid

Mushroom

Shii-take mushroom

Penicillin, Cheese
Fungi cannot transport macromolecular substrates, but the hyphal growth allows a close contact between hyphae and substrate surface. The fungal mycelium synthetises and excretes high quantities of hydrolytic exoenzymes. The resulting contact catalysis is very efficient and the simple products are in close contact to enter the mycelium across the cell membrane to promote biosynthesis and fungal metabolic activities. This contact catalysis by enzymes can explain the logistic model of fungal growth commonly observed (Raimbault, 1981). That point will be discussed further.

\section{Substrates}

All solid substrates have a common feature: their basic macromolecular structure. In general, substrates for SSF are composite and heterogeneous products from agriculture or by-products of agro-industry. This basic macromolecular structure (e.g. cellulose, starch, pectin, lignocellulose, fibres etc..) confers the properties of a solid to the substrate. The structural macromolecule may simply provide an inert matrix (sugarcane bagasse, inert fibres, resins) within which the carbon and energy source (sugars, lipids, organic acids) are adsorbed. But generally, the macromolecular matrix represents the substrate and provides also the carbon and energy source.

Preparation and pre-treatment represent the necessary steps to convert the raw substrate into a form suitable for use, that include:

- size reduction by grinding, rasping or chopping
- physical, chemical or enzymatic hydrolysis of polymers to increase substrate availability by the fungus.

- supplementation with nutrients (phosphorus, nitrogen, salts) and setting the $\mathrm{pH}$ and moisture content, through a mineral solution

- cooking or vapour treatment for macromolecular structure pre-degradation and elimination of major contaminants. Pre-treatments will be discussed under individual applications.

The most significant problem of SSF is the high heterogeneity, which makes difficult to focus one category of hydrolytic processes, and leads to poor trials of modelling. This heterogeneity is of different nature:

- non-uniform substrate structure (mixture of starch, lignocellulose, pectin)

- Variability between batches of substrates, limiting the reproducibility

- Difficulty of mixing solid mass in fermentation, in order to avoid compaction, which causes non uniform growth, gradients of temperature, $\mathrm{pH}$ and moisture, that makes representative samples almost impossible to obtain.

Each macromolecular type of substrate presents different kind of heterogeneity:

Lignocellulose occurs within plant cell walls, which consist of cellulose microfibrils embedded in lignin, hemicellulose and pectin. Each category of plant material contains variable proportion of each chemical compound. Two major problems can limit lignocellulose breakdown: 
- cellulose exists in four recognised crystal structures known as celluloses I, II, III and IV. Various chemical or thermal treatments can change the structure from crystalline to amorphous.

- $\quad$ - different enzymes are necessary in order degrade cellulose, e.g. endo and exo-cellulases plus cellobiase

Pectins are polymers of galacturonic acid with different ratio of methylation and branching. Exo-and endo pectinases and demethylases that hydrolyse pectin into galacturonic acid and methanol. Hemicelluloses are divided in major three groups: xylans, mannans and galactans. Most of hemicelluloses are heteropolymers containing two to four different types of sugar residues.

Lignin represents between 26 to $29 \%$ of lignocellulose, and is strongly bounded to cellulose and hemicellulose, hiding them and protecting them from the hydrolase attack. Lignin peroxidase is the major enzyme involved in lignin degradation. Phanerochaete chrysosporium is the most recognised fungi for lignin degradation.

So, lignocellulose hydrolysis is a very complex process. Effective cellulose hydrolysis requires the synergetic action of several cellulases, hemicellulases and lignin peroxidases.

Despite this, lignocellulose is a very abundant and cheap natural renewable material, so a lot of work has been conducted on its microbial breakdown, specially with fungal species.

Starch is another very important and abundant natural solid substrate. Many microorganisms are capable to hydrolyse starch, but generally its efficient hydrolysis requires previous gelatinization. Some recent works concern the hydrolysis of the raw (crude or native) starch as it occurs naturally.

The chemical structure of starch is relatively simple compared to lignocellulose substrates. Essentially starch is composed of two related polymers in different proportions according to its source: amylose (16-30\%) and amylopectin $(65-85 \%)$. Amylose is a polymer of glucose linked by $\alpha$ 1,4 bonds, mainly in linear chains. Amylopectin is a large highly branched polymer of glucose including also $\alpha-1,6$ bonds at the branch points.

Within the plant, cell starch is stored in the form of granules located in amyloplasts, intracellular organelles surrounded by a lipoprotein membrane. Starch granules are highly variable in size and shape depending on the plant material. Granules contain both amorphous and crystalline internal regions in respective proportions of about 30/70. During the process of gelatinization, starch granules swell when heated in the presence of water, which involves the breaking of hydrogen bonds, especially in the crystalline regions.

Many microorganisms can hydrolyse starch, specially fungi which are then suitable for SSF application involving starchy substrates. Glucoamylase, $\alpha$-amylase, $\beta$-amylase, pullulanase and isoamylase are involved in the processes of starch degradation. Mainly $\alpha$-amylase and glucoamylase are of importance for SSF.

$\alpha$-amylase is an endo-amylase attacking $\alpha-1,4$ bonds in random fashion which rapidly reduce molecular size of starch and consequently its viscosity producing liquefaction. Glucoamylase occurs almost exclusively in fungi including Aspergillus and Rhizopus groups. This exo amylase produces glucose units from amylose and amylopectin chains.

Microorganisms generally prefer gelatinised starch. But large quantity of energy is required for gelatinization so it would be attractive to use organisms growing well on raw (ungelatinised) starch. Different works are dedicated to isolate fungi producing enzymes able to degrade raw starch, as has been done by Soccol et al., (1994), Bergmann et al., (1988) and Abe et al., (1988).

In our laboratory, many studies concerning SSF of cassava, a very common tropical starchy crop, have been conducted with the purpose of upgrading protein content, both for animal feeding using Aspergillus sp. and for direct human consumption, using Rhizopus. Table 4 indicates the protein enrichment with different fungi.fungi.

Table 4. Protein enrichment of Cassava by various selected strains of fungi. (Raimbault et al., 1985)

\begin{tabular}{|l|l|l|l|l|}
\hline Inoculum & & & Composition & (\% dry basis) \\
\hline Strain & Source & $\begin{array}{l}\text { Time } \\
\text { (h) }\end{array}$ & Protein & Total Sugar \\
\hline Aspergillus niger no.10 & Cassava & 25 & 16.5 & 35.6 \\
\hline Aspergillus awamori no.12 & Koji & 30 & 16.3 & 35.1 \\
\hline Aspergillus usamii no.M140 & Koji & 30 & 15.6 & 29.5 \\
\hline Monilia sitophila no. 27 & Pozol & 42 & 15.1 & 32.3 \\
\hline
\end{tabular}




\begin{tabular}{|l|l|l|l|l|}
\hline Rhizopus sp. no. 7 & Cassava & 48 & 14.9 & 39.3 \\
\hline Aspergillus oryzae no.M84 & Koji & 30 & 14.8 & 30.0 \\
\hline Aspergillus sp. no. B1 & Banana & 30 & 14.7 & 39.1 \\
\hline Aspergillus sp. no. 11 & Tempeh & 30 & 14.3 & 34.0 \\
\hline Aspergillus niger no. 31 & Cassava & 30 & 14.3 & 34.5 \\
\hline Aspergillus sp. no. 14 & Cassava & 30 & 14.2 & 37.9 \\
\hline Aspergillus terricola no. R3 & Ragi & 30 & 14.1 & 10.9 \\
\hline Aspergillus sp. no. M101 & Tempeh & 30 & 14.0 & 31.4 \\
\hline Aspergillus sp. no. 72 & Banana & 30 & 13.8 & 28.2 \\
\hline Aspergillus awamori no. 13 & Koji & 48 & 13.0 & 38.8 \\
\hline Aspergillus sp. no. M147 & Koji & 30 & 12.7 & 32.4 \\
\hline Aspergillus niger no. 17 & Cassava & 30 & 12.0 & 45.2 \\
\hline Aspergillus sp. no. 39 & Banana & 30 & 11.1 & 40.0 \\
\hline Aspergillus sp. no. M82 & Tempeh & 30 & 10.9 & 38.0 \\
\hline Raw cassava & -- & -- & 2.50 & 90.00 \\
\hline
\end{tabular}

Recently good results were obtained by Soccol in the protein enrichment of cassava and cassava bagasse using selected strains of Rhizopus. Biotransformed starchy flours were produced containing $10-12 \%$ of good quality protein, comparable to cereal. Such biotransformed cassava flour can be used as cereal substitute for breadmaking up to a level of $20 \%$, without any perceivable change by the consumer.

\section{Biomass Measurement}

Biomass is a fundamental parameter in the characterisation of microbial growth. Its measurement is essential for kinetic studies on SSF. Direct determination of biomass in SSF is very difficult due to the problem of separating the microbial biomass from the substrate. This is especially true for SSF processes involving fungi, because the fungal hyphae penetrate into and bind tightly to the substrate. On the other hand, for the calculation of growth rates and yields, it is the absolute amount of biomass which is important. Methods that have been used for biomass estimation in SSF belong to one of the following categories.

\section{Direct evaluation of biomass}

Complete recovery of fungal biomass is possible only under artificial circumstances in membrane filter culture, because the membrane filter prevents the penetration of the fungal hyphae into the substrate (Mitchell et al, 1991). The whole of the fungal mycelium can be recovered simply by peeling it off the membrane and weighing it directly or after drying. Obviously, this method cannot be used in actual SSF. However, it could find application in the calibration of indirect methods of biomass determination. Indirect biomass estimation methods should be calibrated under conditions as similar as possible to the actual situation in SSF. The global mycelium composition could be estimated through analysis of the mycelium cultivated in LSF in conditions as close as possible to SSF cultivation.

Microscopic observations can also represent a good way to estimate fungal growth in SSF. Naturally, optic examination is not possible at high magnitude but only at stereo microscope. Scanning Electron Microscope (SEM) is a useful tool to observe the pattern of growth in SSF. New approaches and researches are developed for image analysis by computer software in order to evaluate the total length or volume of mycelium on SEM photography. Another new very promising approach is the Confocal Microscopy, based on specific reaction of fungal biomass with specific fluorochrome probes. Resulting 3D images of biomass can open new ways to appreciate and measure biomass in situ in a near future.

Since direct measurement of exact biomass in SSF is a very difficult task, then other approaches have been preferred. That for, the global stoichiometric equation of microbial growth can be considered:preferred. That for, the global stoichiometric equation of microbial growth can be considered:

\title{
Carbon source + Water + Qxygen + Phosphorus + Nitrogen
}

\author{
Biomass + CO2 + Metabolites + Heat
}


Raimbault, M.

Variation in each component is strictly related to the variation of others when all coefficients are maintained constants. Then, measuring one of them allows to determine the evolution of the others.

\section{Metabolic measurement of biomass}

- Respiratory metabolism

Oxygen consumption and carbon dioxide release result from respiration, the metabolic process by which aerobic micro-organisms derive most of their energy for growth. These metabolic activities are therefore growth associated and can be used for the estimation of biomass synthesis.

As carbon compounds within the substrate are metabolised, they are converted into biomass and carbon dioxide. Production of carbon dioxide causes the weight of fermenting substrate to decrease during growth, and the amount of weight lost can be correlated to the amount of growth that has occurred.
Growth estimation based on carbon dioxide release or oxygen consumption assumes that the metabolism of these compounds is completely growth associated, which means that the amount of biomass produced per unit of gas metabolised must be constant. Sugama and Okazaki (1979) reported that the ratio of $\mathrm{mg} \mathrm{CO}_{2}$ evolved to $\mathrm{mg}$ dry mycelia formed by Aspergillus oryzae on rice ranged from 0.91 to $1.26 \mathrm{mg} \mathrm{CO}_{2}$ per mg dry mycelium. A gradual increase in this ratio was observed late in growth due to endogenous respiration. Drastic changes can be observed for the respiratory quotient which commonly changes with the growth phase, i.e: germination, rapid and vegetative growth, secondary metabolism, conidiation and degeneration of the mycelium. Evolution of $\mathrm{CO}_{2}$ and $\mathrm{O}_{2}$ during SSF of Rhizopus on cassava is presented in fig 1 .

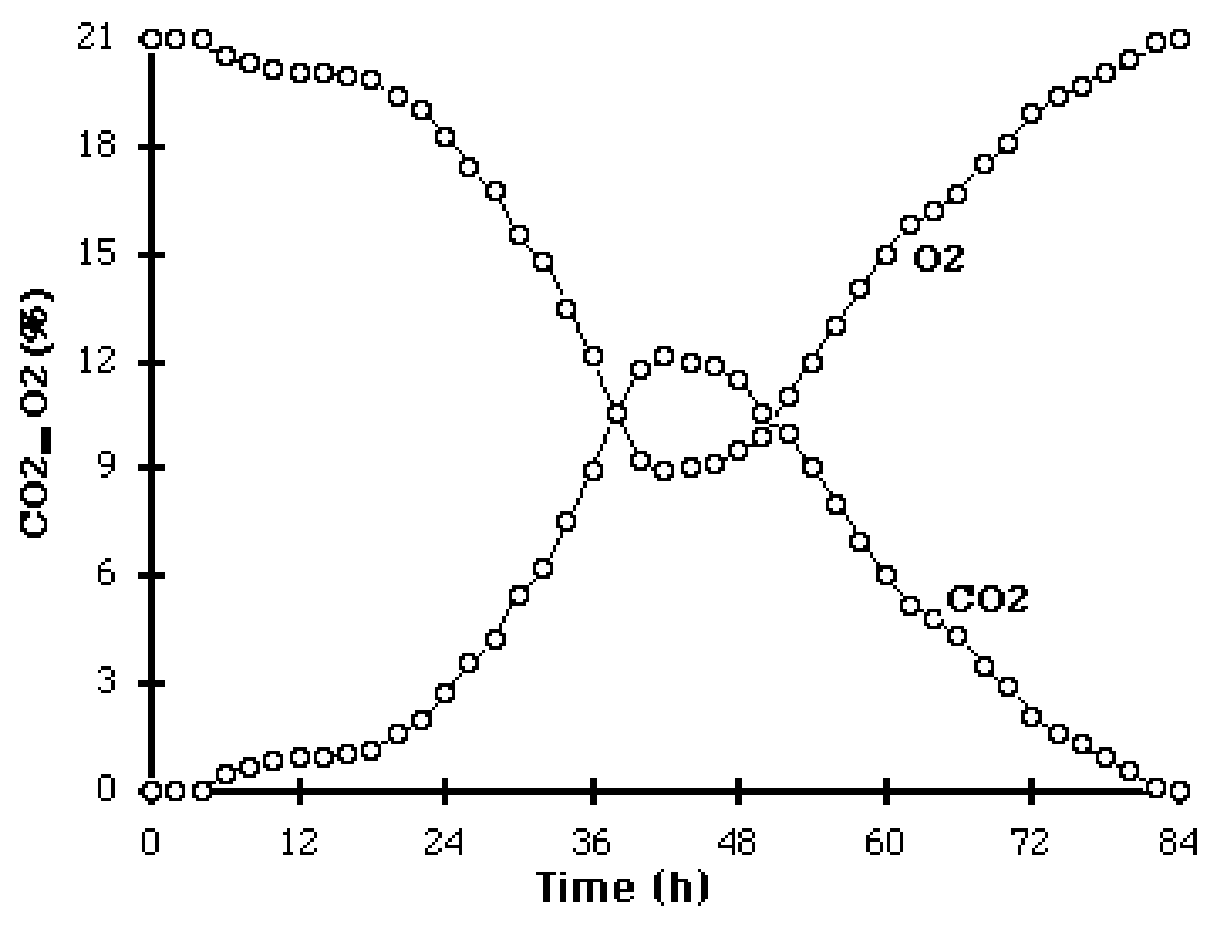

Figure 1.- Kinetic evolution of $\mathrm{CO}_{2}$ and $\mathrm{O}_{2}$ in air flow during fermentation of Rhizopus on cassava.

The measurement of either carbon dioxide evolution or oxygen consumption is most powerful when coupled with the use of a correlation model. The term correlation model is used here to denote a model that correlates biomass with a measurable parameter. Correlation models are not growth models as such, since they make no predictions as to how the measurable parameter changes with time. The usefulness of correlation models is that a biomass profile can be constructed by following the profile of the parameter during growth.

Application of these correlation models involving prediction of growth from oxygen uptake rates or carbon dioxide evolution rates requires the use of numerical techniques to solve the differential equations. A computer and appropriate software is therefore essential. If both the 
monitoring and computational equipment is available, then these correlation models provide a powerful mean of biomass estimation since continuous on-line measurements can be made. Other advantages of monitoring effluent gas concentrations with paramagnetic and infrared analysers include the ability to monitor the respiratory quotient to ensure optimal substrate oxidation, the ability to incorporate automated feedback control over the aeration rate, and the non-destructive nature of the measurement procedure.

The metabolic activity in SSF is very important for studying all theoretical and practical aspects of respirometric measurement of fungal biomass cultivated in SSF. Various authors reported data concerning laboratory and scale up experiments on respirometric measurement in several applications (Raimbault, 1981; Deschamps et al., 1982; Bajracharya et al., 1980). An international training course was recently dedicated to advances and techniques to study fungal growth on SSF (Raimbault et al., 1998).

\section{- Production of extracellular enzymes or primary metaboli-} tes

Another metabolic activity that may be growth associated is extracellular enzyme production. Okazaki and coworkers (1980) claimed that the $\alpha$-amylase activity was directly proportional to mycelial weight for Aspergillus oryzae grown in SSF on steamed rice. For growth of Agaricus bisporus on mushroom compost, mycelial mass was directly proportional to the extracellular laccase activity for 70 days (Wood, 1979). In our works we have generally observed a good correlation between growth and hydrolytic enzymes such as amylases, cellulases or pectinases (Raimbault, 1981; Roussos et al., 1991b, 1993).

Also, we have frequently observed a good correlation between mycelial growth and organic acid production, which can be estimated from $\mathrm{pH}$ measurement or correlated by HPLC analysis on extracts. In the case of Rhizopus, Soccol (1992) demonstrated a close correlation between fungal protein (biomass) and organic acids (citric, fumaric, lactic or acetic).

\section{Biomass Components}

The biomass can also be estimated from measurements of a specific component, as long as the composition of the biomass is constant and stable and the fraction of the component representative.

\section{Protein content:}

The most readily measured biomass component is protein. We used the protein content (as determined by the Lowry method) to measure the growth rate of Aspergillus niger on cassava meal (Raimbault and Alazard, 1980). Growth of
Chaetomium cellulolyticum on wheat straw was determined from TCA insoluble nitrogen using the Kjeldahl method (Laukevics et al., 1984); biomass protein was then calculated as 6,25 times this value. In all cases the protein content of the biomass was assumed to be constant. Values of biomass protein content measured by the Biuret method were consistent with those measured by the Kjeldahl method. But, unfortunately, the Biuret method was not suitable for application to SSF because of nonspecific interference by substrate starch. The Folin method is more sensitive and allowed a greater dilution of the sample, which avoided interference from the starch in the substrate. Therefore we have chosen the Folin technique to measure protein enrichment in starchy substrates.

\section{$\underline{\text { Nucleic acids }}$}

DNA content has been used to estimate the biomass of Aspergillus oryzae on rice (Bajracharya and Mudgett, 1980). The method was calibrated using the DNA contents of fungal mycelia obtained in submerged culture. DNA contents were higher during early growth and then decreased, levelling off as the stationary phase was approached. The method was corrected for the DNA content of rice, which remained unchanged since Aspergillus oryzae did not produce extracellular DNases. Methods based on DNA or RNA determination are reliable only if there is little nucleic acid in the substrate and no interfering chemicals are present.

\section{$\underline{\text { Glucosamine }}$}

Glucosamine is a useful compound for the estimation of fungal biomass, taking advantage of the presence of chitin, poly-Nacetylglucosamine, in the cell walls of many fungi. Interference with this method may occur when using complex agricultural substrates containing glucosamine in glucoproteins (Aidoo et al., 1981).

The accuracy of the glucosamine method for determination of fungal biomass depends on establishing a reliable conversion factor relating glucosamine to mycelial dry weight (Sharma et al., 1977). However, the proportion of chitin in the mycelium will vary with age and the environmental conditions. Mycelial glucosamine contents ranged from 67 to $126 \mathrm{mg}$ per g dry mycelium. Another disadvantage of this method is the tedious extraction procedures and processing times over 24 hours.

\section{$\underline{\text { Ergosterol }}$}

Ergosterol is the predominant sterol in fungi. Glucosamine estimation was therefore compared with the estimation of ergosterol for the determination of growth of Agaricus bisporus (Matcham et al, 1985). In solid cultures, directly proportional relationships for glucosamine and ergosterol 
against linear extension of the mycelium were obtained. Determination of ergosterol was claimed to be more convenient than glucosamine. It could be recovered and separated by HPLC and quantified simply by spectrophotometry, providing a sensitive index of biomass at low levels of growth. HPLC was necessary to separate the ergosterol from sterols endogenous to the solid substrate. However, Nout et al., (1987) showed that the ergosterol content of Rhizopus oligosporus varied from 2 to 24 micrograms per mg dry biomass, depending on the culture conditions, aeration and substrate composition, concluding that it was an unreliable method for following growth.

\section{Physical measurement of biomass}

Peñaloza (1991) evaluated mycelial growth, based on the difference in the electric conductivity between biomass and the substrate. Good correlation with biomass was obtained and a model was proposed.

Auria et al.,(1990) monitored the pressure drop in a packed bed during SSF of Aspergillus niger on a model solid substrate consisting of ion exchange resin beads. Pressure drop was closely correlated with protein production. Pressure drop is a parameter that is simple to measure and can be measured on-line. Further studies are required to determine whether the use of pressure drop is generally applicable for monitoring growth in SSF bioreactors under forced aeration. An interesting point of this physical technique resides in the fact that it is sensible to conidiation: early conidiophore stage makes the pressure to drop drastically and a breaking point can be easily observed.

In conclusion, the measurement of biomass in SSF is important to follow the kinetics of growth in relation to the metabolic activity. Measurement of metabolic activity by carbon dioxide evolution or oxygen consumption can be generally applied, whereas extracellular enzyme production will only be useful when enzyme production is reasonably growth-associated.

Vital staining with fluorescein diacetate has potential in providing basic information as to the mode of growth of fungi on complex solid surfaces, as this method can show the distribution of metabolic activity within the mycelium. But it cannot be measured on line.

On the other hand, in the production of protein enriched feeds, the protein content itself is of greater importance than the actual biomass concentration, and the variation in biomass protein content during growth becomes less relevant.

Overall, oxygen uptake and carbon dioxide evolution methods are probably the most promising techniques for biomass estimation in aerobic SSF as they provide on-line information. The monitoring and computing equipment is relatively expensive and will not be suitable for low technology or rural applications. No method is ideally suited to all situations, so the method most appropriate to a particular SSF application must be chosen in each case on the basis of simplicity, cost and accuracy. A good strategy can be a combination of several techniques based on the determination of different parameters that can correlate actual biomass with the material balance.

\section{Environmental Factors}

Environmental factors such as temperature, $\mathrm{pH}$, water activity, oxygen levels and concentrations of nutrients and products significantly affect microbial growth and product formation. In submerged stirred cultures, environmental control is relatively simple because of the homogeneity of the suspension of microbial cells and of the solution of nutrients and products in the liquid phase.

The low moisture content of SSF enables a smaller reactor volume per substrate mass than LSF and also simplifies product recovery (Moo-Young et a1., 1983). However, serious problems arise with respect to mixing, heat exchange, oxygen transfer, moisture control and gradients of $\mathrm{pH}$, nutrient and product as a consequence of the heterogeneity of the culture.

The latter characteristic of SSF render the measurement and control of the above mentioned parameters difficult, laborious and often inaccurate, thereby limiting the industrial potential of this technology (Kim et al, 1985). Due to these problems, the micro-organisms that have been selected for SSF are the more tolerant to a wide range of cultivation conditions (Mudgett, 1986).

\section{Moisture content and Water activity (Aw)}

SSF process can be defined as microbial growth on solid particles without the presence of free water. The water present in SSF systems exists in a complexed form within the solid matrix or as a thin layer either absorbed to the surface of the particles or less tightly bound within the capillary regions of the solid. Free water will only occur once the saturation capacity of the solid matrix is exceeded. However, the moisture level at which free moisture becomes apparent varies considerably between substrates and is dependant upon their water binding characteristics. For example, free water is observed when the moisture content exceeds $40 \%$ in maple bark and $50-55 \%$ in rice and cassava (Oriol et al., 1988a). With most lignocellulosic substrates free water becomes apparent before the $80 \%$ moisture level is reached (Moo-Young et al., 1983).

The moisture levels in SSF processes, which vary between 30 and $85 \%$, has a marked effect on growth kinetics, as 
shown on Figure 2 (Oriol et al., 1988b). The optimum moisture level for the cultivation of Aspergillus niger on rice was $40 \%$, whereas on coffee pulp the level was $80 \%$, which illustrates the unreliability of moisture level as a parameter for predicting microbial growth. It is now generally accepted that the water requirements of microorganisms should be defined in terms of the water activity (Aw) rather than the water content of the solid substrate. Aw is a thermodynamic parameter defined in relation to the chemical potential of water. Aw is related to the condensed phase of absorbed water, but it is well correlated (less than $0.2 \%$ error) to the relative humidity $(\mathrm{RH})$. Therefore: $\mathrm{Aw}=\mathrm{RH} / 100=\mathrm{p} / \mathrm{po}$, where $\mathrm{p}$ is the vapour pressure of the water in the substrate and po is the vapour pressure of pure water at the corresponding temperature, $\mathrm{R}$ being the ideal gas constant (Griffin, 1981). Aw represents the availability of water for reaction in the solid substrate.

The reduction of Aw has a marked effect on microbial growth. Typically, a reduction in Aw extends the lag phase, decreases the specific growth rate, and results in low amount of biomass produced (Oriol et al., 1988b), as shown in fig.2. In general, bacteria require higher values of Aw for growth than fungi, thereby enabling fungi to compete more successfully at the Aw values encountered in SSF processes. With the exception of halophilic bacteria, few others grow at Aw values below 0.9 and most bacteria require considerably higher minimum Aw values for growth. Some fungi, on the other hand, stop growing only at Aw values as low as 0.62 and a number of fungi used in SSF processes have minimum growth Aw values between 0.8 and 0.9

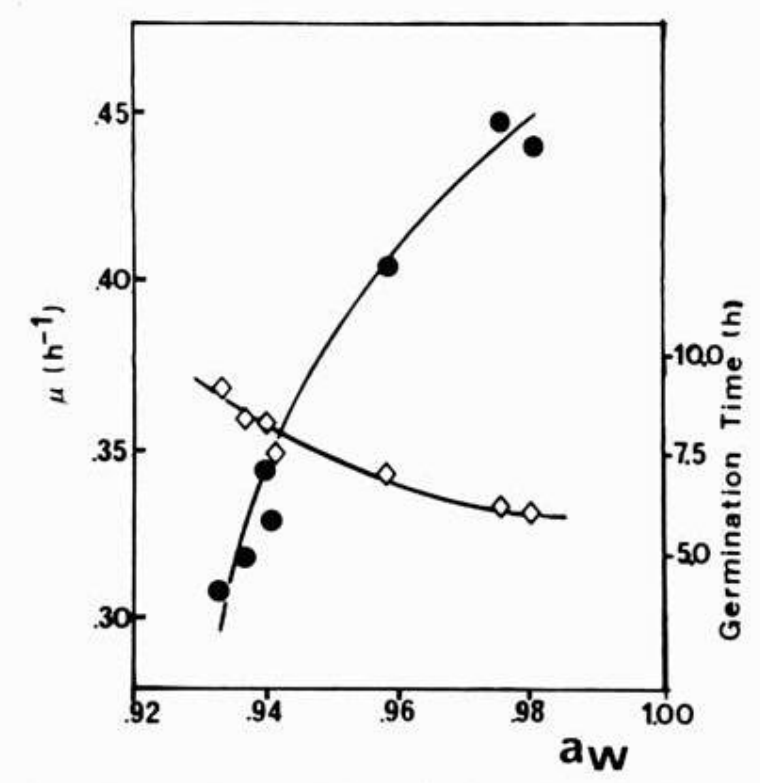

Fig.2. Evolution of the specific growth rate (- -$)$ and of the germination time $(-\diamond-)$ as a function of the initial water activity of the medium

The optimum moisture content for growth and substrate utilisation is between 40 and $70 \%$ but depends upon the organism and the substrate used for cultivation. For example, cultivation of Aspergillus niger on starchy substrates, such as cassava (Raimbault and Alazard, 1980) and wheat bran (Nishio et al., 1979), was optimal at moisture levels considerably lower than on coffee pulp (Penaloza et al., 1991) or sugarcane bagasse (Roussos et al., 1991a, 1991b). This is probably because of the greater water holding capacity of the latter substrate (Oriol et al., 1988b). The optimum Aw for growth of a limited number of fungi used in SSF pro- cesses was at least 0.96, whereas the minimum Aw required for growth was generally greater than 09 . This suggests that fungi used in SSF processes are not especially xerophilic. The optimum Aw values for sporulation in Trichoderma viride and Penicillium roqueforti were lower than those for growth (Gervais et al., 1988). Maintenance of the Aw at the growth optimum would allow fungal biomass to be produced without sporulation.

\section{Temperature and Heat Transfer}


Stoichiometric global equation of respiration is highly exothermic and heat generation by high levels of fungal activity within the solids lead to thermal gradients because of the limited heat transfer capacity of solid substrates. In aerobic processes, heat generation may be approximated from the rate or $\mathrm{CO}_{2}$ evolution or $\mathrm{O}_{2}$ consumption. Each mole of $\mathrm{CO}_{2}$ produced during the oxidation of carbohydrates releases $673 \mathrm{Kcal}$. Therefore, it is important to measure $\mathrm{CO}_{2}$ evolution during SSF because it is directly related to the risk of temperature increase. Detailed calculations of the relation between respiration, metabolic heat and temperature were discussed in early works on SSF with Aspergillus niger growing on cassava or potato starch (Raimbault, 1981). The overall rate or heat transfer may be limited by the rates of intra- and inter-particle heat transfer and by the rate at which heat is transferred from the particle surface to the gas phase. The thermal characteristics of organic material and the low moisture content in SSF are especially difficult conditions for heat transfer. SaucedoCastañeda et al., 1990 developed a mathematical model for evaluating the fundamental heat transfer mechanism in static SSF and more specifically to assess the importance of convection and conduction in heat dissipation. This model can be used as a basis for automatic control of static bioreactors.

Heat removal is probably the most crucial factor in large scale SSF processes. Conventional convection or conductive cooling devices are inadequate for dissipating metabolic heat due to the poor thermal conductivity of most solid substrates and results in unacceptable temperature gradients. Only evaporative cooling devices provide sufficient heat elimination capacity. Although the primary function of aeration during aerobic solid state cultivations was to supply oxygen for cell growth and to flush out the produced carbon dioxide, it also serves a critical function in heat and moisture transfer between the solids and the gas phase. The most efficient process for temperature control is water evaporation.

Maintaining constant temperature and moisture content simultaneously in large scale SSF is generally difficult, but using the proper ancillary equipment can do this. The reactor type can have a large influence on the quality of temperature control achieved. It depends highly of the type of SSF: static on clay or vertical exchangers, drums or mechanically agitated.

\section{Control of $\mathrm{pH}$ and risks of contamination}

The $\mathrm{pH}$ of a culture may change in response to metabolic activities. The most obvious reason is the secretion of organic acids such as citric, acetic or lactic, which will cause the $\mathrm{pH}$ to decrease, in the same way than ammonium salts consumption. On the other hand, the assimilation of organic acids which may be present in certain media will lead to an increase in $\mathrm{pH}$, and urea hydrolysis will result in alkalinisation. The kinetics of $\mathrm{pH}$ variation depends high- ly on the microorganism. With Aspergillus sp., Penicillium $s p$. , and Rhizopus sp. the $\mathrm{pH}$ can drop very quickly below 3.0; for other types of fungi, like Trichoderma, Sporotrichum, Pleurotus sp. the $\mathrm{pH}$ is more stable between 4 and 5 . Besides, the nature of the substrate has a strong influence on $\mathrm{pH}$ kinetics, due to the buffering effect of lignocellulosic materials.

We have used a mixture of ammonium salt and urea to control the $\mathrm{pH}$ decrease during growth of A. niger on starchy substrates (Raimbault, 1981). A degree of $\mathrm{pH}$ control may be obtained by using different ratios of ammonium salts and urea in the substrate. Hydrolysis of urea liberates ammonia, which counteracts the rapid acidification resulting from uptake of the ammonium ion (Raimbault and Alazard. 1980). In this manner, we obtained optimal growth of Aspergillus niger on granulated cassava meal when using a 3:2 ratio (on a nitrogen basis) of ammonium to urea. We observed that during the first stage of cultivation the $\mathrm{pH}$ increased as the urea was hydrolysed. During the subsequent rapid growth stage, ammonium assimilation exceeded the rate of urea hydrolysis and the $\mathrm{pH}$ decreased, but increased again in the stationary phase. During cultivation, the $\mathrm{pH}$ remained within the limits of $\mathrm{pH} 5$ to $\mathrm{pH}$ 6.2, whereas a lower urea concentration resulted in a rapid decrease in $\mathrm{pH}$.

In a similar way, $\mathrm{pH}$ adjustment during pilot plant cultivation of Trichoderma viride on sugar-beet pulp was effective by spraying with urea solutions due to the urease activity of the micro-organism that caused an increase in pH by producing ammonia (Durand et al., 1988).

Finally, in fungal or yeast SSF, bacterial contamination may be minimised or prevented by employing a suitably low $\mathrm{pH}$.

\section{Oxygen uptake}

Aeration fulfils four main functions in SSF, namely (i) to maintain aerobic conditions, (ii) to desorb carbon dioxide, (iii) to regulate the substrate temperature and (iv) to regulate the moisture level. The gas environment may significantly affect the relative levels of biomass and enzyme production. In aerobic LSF oxygen supply is often the growth limiting factor due to the low solubility of oxygen in water. In contrast, a solid state process allows free access of atmospheric oxygen to the substrate. Therefore, aeration may be easier than in submerged cultivations because of the rapid rate of oxygen diffusion into the water film surrounding the insoluble substrate particles, and also because of the very high surface of contact between gas phase, substrate and aerial mycelium. The control of the gas phase and air flow is a simple and practical mean to regulate gas transfer and generally no oxygen limitation is observed in SSF when the solid substrate is particular. It is important to maintain a good ba- 
lance between the three phases in SSF (Auria, 1990; Saucedo-Castañeda et al., 1990).. By this very simple aeration process, it is also possible to induce metabolic reactions, either by water stress, heat stress or temperature changes, all processes that can drastically change biochemical or metabolic behaviour.

\section{Concluding Remarks}

SSF is a well-adapted process for cultivation of fungi on vegetal materials which are breakdown by excreted hydrolytic enzymes. In contrast with LSF where water is in large excess, water activity is a limiting factor in SSF. On the other hand, oxygen is a limiting factor in LSF but not in $\mathrm{SSF}$, where aeration is promoted by the porous and particular structure and by the high surface are of contact which facilitate mass transfer between gas and liquid phases.

SSF are aerobic processes where respiration is fundamental for energy supply but, because respiratory metabolism is highly exothermic, severe limitation of growth can occur when heat transfer is not efficient enough to avoid temperature increase.

This is why it is so important to study and control respirometry in SSF. We have developed a laboratory technique to measure $\mathrm{CO}_{2}$ and $\mathrm{O}_{2}$ on line in SSF.

\section{References}

Abe, J.I., Bergmann, F.W., Obata, K. and Hizukuri, S. (1988). Production of raw-starch digesting amylase of Aspergillus sp. K-27. Applied Microbiology and Biotechnology 27 :20-27.

Agosin, D., Jarpa, S., Rojas, E. and Espejo, E. (1989). Solid state fermentation of pine sawdust by brown-rot fungi. Enzyme and Microbial Technology 11:511-517.

Alazard, D. and Raimbault, M. (1981). Comparative study of amylolytic enzymes production by Aspergillus niger in liquid and solid state cultivation. European Journal of Applied Microbiology and Biotechnology 12:113-117.

Auria, R., Hernandez, S., Raimbault, M. and Revah, S. (1990). Ion exchange resin: a model support for solid state growth fermentation of Aspergillus niger. Biotechnology Techniques 4:391-396.

Bajracharya, R. and Mudgett, R.E. (1980). Effects of controlled gas environments in solid substrate fermentations of rice. Biotechnology and Bioengineering 22:2219-2235.

Barrios-Gonzales, J., Tomasini, A, Viniegra-Gonzalez, G. and Lopez, L. (1988). Penicillin production by solid state fermentation. in: Solid State Fermentation in Bioconversion of Agro-industrial Raw Materials, Ed. M. Raimbault, ORSTOM, Montpellier Fr. , pp. 39-51.

Bergmann, F.W., Abe, J.I. and Hizukuri, S. (1988). Selection of microorganisms which produce raw-starch degrading enzymes Applied Microbiology and Biotechnology 27 : 443-446.

Cabello, A. and Conde, J. (1985). Evaluation of newer methods of pretreatment for biological utilization of cellulosic residues. Acta Biotechnologica 5:191-196.

Deschamps, F., Raimbault, M. and Senez, J.C. (1982). Solid state fermentation in the development of agro-food by-products. Industry and Environment 5:27-30.

Doelle, H.W., Mitchell, D.A. and Rolz, C.E. (1992). Solid Substrate Cultivation. Elsiever Sci. Publ. 1td;London \& New York; 466 p.

Durand, A. and Chereau, D. (1988). A new pilot reactor for solid state fermentation: application to the protein enrichment of sugar beet pulp. Biotechnology and Bioengineering 31:476-486.

Durand, A., Renaud, R., Maratray, J., Almanza, S. (1997). The INRA-Dijon Reactors: Designs and applications. In Roussos, S., Lonsane, B.K., Raimbault, M. and ViniegrazGonzalez, G. (Eds.), Advances in solid state fermentation, Kluwer Acad. Publ., Dordrecht, chapter 7 pp. 71-92.

Enriquez, A, and Rodriguez, H. (1983). High productivity and good nutritive values of cellulosic bacteria grown on sugarcane bagasse. Biotechnology and Bioengineering 25:877-880.

Fernandez, M., Perez-Correa, J.R., Solar, E. and Agosin, E. (1996). Automation of a solid substrate cultivation pilot reactor. Bioprocess Engineering 16:1-4.

Gervais, P., Molin, P., Grajek, W. and Bensoussan, M. (1988). Influence of the water activity of a solid substrate on the growth rate and sporogenesis of filamentous fungi. Biotechnology and Bioengineering 31:457-463.

Griffin, D.M. (1981). Water and microbial stress. Advances in Microbial Ecology 5:91-136.

Moo-Young, M., Moriera, A.R. and Tengerdy, R.P. (1983). Principles of solid state fermentation. In The filamentous fungi, Vol. 4, Fungal Biotechnology. Smith J.E, Berry D.R \& Kristiansen B. Eds., Edward Arnold Publishers, London, pp. 117-144. 
Hesseltine, C.W. (1972). Biotechnology report on solid state fermentations. Bitechnology and Bioengineering $14: 517-532$.

Kim, J.H., Hosobuchi, M., Kishimoto, M., Seki, T., Yoshida, T., Taguchi, H. and Ryu, D.D.Y. (1985). Cellulase production by a solid state culture system. Biotechnology and Bioengineering 27:1445-1450.

Kumar, P.K.R. (1987). Microbial production of gibberellic acid. PhD Thesis, Mysore University, Mysore, India.

Laukevics, J.J., Apsite, A.F., Viesturs, U.E. and Tengerdy, R.P. (1984). Solid substrate fermentation of wheat straw to fungal protein. Biotechnology and Bioengineering 26: 1465-1474.

Matcham, S.E., Jordan, B.R. and Wood, D.A. (1985). Estimation of fungal biomass by three different methods. Applied Microbiology and Biotechnology, 21:108-112.

Mitchell, D.A., Gumbira-Said, E., Greenfield, P.F. and Doelle, H.W. (1991). Protein measurement in solid state fermentation. Biotechnology Techniques 5:437-442.

Mudgett, R.E. (1986). Solid state fermentations. in: Manual of Industrial Microbiology \& Biotechnology, American Society for Microbiology, Washigton D.C., pp. 66-83.

Nishio, N., Tai, K. and Nagai, S. (1979). Hydrolase production by Aspergillus niger in solid state cultivation. European Journal Microbiology and Biotechnology 8:263270.

Nout, M.J.R., Bonants-van Laarhoven, T.M.G., de Jongh, P. and de Koster, P.G. (1987). Ergosterol contents of Rhizopus oligosporus NRRL 5905 grown in liquid and solid substrates. Applied Microbiology and Biotechnology 26:456-461.

Okazaki, N., Sugama, S. and Tanaka, T. (1980). Mathematical model of surface culture of koji mold. Journal of Fermentation Technology 58:471-476.

Oriol, E., Schettino, B., Viniegra-Gonzalez, G. and Raimbault, M. (1988a). Solid state culture of Aspergillus niger on support. Journal of Fermentation Technology 66:57-62.

Oriol, E., Raimbault, M., Roussos, S. and ViniegraGonzales, G. (1988b). Water and water activity in the solid state fermentation of cassava starch by Aspergillus niger. Applied Microbiology and Biotechnology 27:498-503.

Peñaloza, W., Davey, C.L., Kell, D.B. and Hedger, J.N. (1991). Real time monitoring of the accretion of Rhizopus oligosporus biomass during the solid substrate tempeh fermentation. World Journal of Microbiology and Biotechnology 7:248-259.

Raimbault, M. - (1981). "Fermentation en milieu solide: croissance de champignons filamenteux sur substrats amylacés". Edited by: ORSTOM-Paris; Série Travaux et Documents $\mathrm{n}^{\circ} 127$; $291 \mathrm{p}$.

Raimbault, M. and Alazard, D. (1980). Culture method to study fungal growth in solid fermentation. European Journal of Applied Microbiology and Biotechnology 9:199-209.

Raimbault, M., Revah, S., Pina, F. and Villalobos, P. (1985). Protein enrichment of cassava by solid state fermentation using molds isolated from traditional foods. Journal of Fermentation Technology 63:395-399.

Raimbault, M., Soccol, C.R. and Chuzel, G. (1998). International training course on solid state fermentation. Document ORSTOM, Montpellier France , ${ }^{\circ} 1$; pp. 204.

Rodriguez, J.A., Bechtstedt, R., Echavarria, J., Sierra, N., Delgado, G. and Daniel, A. (1986). Optimization of solid state fermentation of citrus dried peel by Aspergillus in a packed bed column. Acta Biotecnologica 6:254-258.

Roussos, S. (1985). Croissance de T. harzianum par FMS: physiologie, sporulation et production de cellulases. Thèse de Doctorat, Université Provence, Marseille Fr. , Orstom Ed.

Roussos, S., Olmos, A., Raimbault, M., SaucedoCastañeda, G. and Lonsane, B.K. (1991a). Strategies for large scale inoculum development for solid state fermentation system : Conidiospores of Trichoderma harzianum. Biotechnology Techniques 5:415-420.

Roussos, S., Raimbault, M., Viniegra-Gonzalez, G., Saucedo-Castañeda, G. and Lonsane, B.K. (1991b). Scaleup of cellulases production by Trichoderma harzianum on a mixture of sugar cane bagasse and wheat bran in solid state fermentation system. Micologia Neotropical Aplicada 4:83-98.

Roussos, S., Raimbault, M., Prébois, J.P. and Lonsane, B.K. (1993). Zymotis, a large scale solid state fermenter : Design and evaluation. Applied Biochemistry and Biotechnology 42:37-52.

Saucedo-Castañeda, G., Gutierrez-Rojas, M., Bacquet, G., Raimbault, M. and Viniegra-Gonzalez, G. (1990). Heat transfert simulation in solid substrate fermentation. Biotechnology and Bioengineering 35:802-808. 
Saucedo-Castañeda, G., Lonsane, B.K., Navarro, J.M., Roussos, S. and Raimbault, M. (1992a). Potential of using a simple fermenter for biomass built up, starch hydrolysis and ethanol production: Solid state fermentation system involving Schwanniomyces castellii, Applied Biochemistry and Biotechnology 36:47-61.

Saucedo-Castañeda, G., Lonsane, B.K., Krishnaiah, M.M., Navarro, J.M., Roussos, S. and Raimbault, M. (1992b). Maintenance of heat and water balances as a scale-up criterion for the production of ethanol by Schwanniomyces castellii in a solid state fermentation system. Process Biochemistry 27:97-107.

Senez, J.C., Raimbault, M. and Deschamps, F. (1980). Protein enrichment of starchy substrates for animal feeds by solid state fermentation. World Animal Review 35: 3640.

Sharma, P.D., Fisher, P.J. and Webster, J. (1977). Critique of the chitin assay technique for the estimation of fungal biomass. Transactions of British Mycological Society 69 : 479-483.

Soccol, C.R. (1992). Physiologie et métabolisme de Rhizopus en culture solide et submergée, en relation avec la dégradation d'amidon cru et la production d'acide L(+) lactique. $\mathrm{PhD}$ Thesis, Université Technologique de Compiègne, France, pp. 219.
Soccol, C., Marin, B., Raimbault, M. and Lebeault, J.M. (1994). Breeding and growth of Rhizopus in raw cassava by solid state fermentation. Applied Microbiology and Biotechnology 41:330-336.

Sugama, S., and Okazaki, N. (1979). Growth estimation of Aspergillus oryzae cultured on solid media. Journal of Fermentation Technology 57 : 408-412.

Tengerdy, R.P. (1985). Solid substrate fermentation. Trends in Biotechnology 3:96-99.

Trejo-Hernandez, M.R., Raimbault, M., Roussos, S. and Lonsane, B.K. 1992. Potencial of solid state fermentation for production of ergot alkaloids. Letters in Applied Microbiology 15:156-159.

Trejo-Hernandez, M.R., Lonsane, B.K., Raimbault, M. and Roussos, S. 1993. Spectra of ergot alkaloids produced by Claviceps purpurea 1029c in solid state fermentation system: Influence of the composition of liquid medium used for impregnating sugar cane pith bagasse. Process Biochemistry 28:23-27.

Wood, D.A. (1979). A new method for estimating biomass of Agaricus bisporus in a solid substrate, composted wheat straw. Biotechnology Letters 1:255-260. 